\title{
A comparison of the quality of image acquisition between the incident dark field and sidestream dark field video-microscopes
}

Edward Gilbert-Kawai ${ }^{1 *}$, Jonny Coppel ${ }^{1}$, Vassiliki Bountziouka ${ }^{2}$, Can Ince ${ }^{3}$, Daniel Martin ${ }^{1,4}$ and for the Caudwell Xtreme Everest and Xtreme Everest 2 Research Groups

\begin{abstract}
Background: The 'Cytocam' is a third generation video-microscope, which enables real time visualisation of the in vivo microcirculation. Based upon the principle of incident dark field (IDF) illumination, this hand held computer-controlled device was designed to address the technical limitations of its predecessors, orthogonal polarization spectroscopy and sidestream dark field (SDF) imaging. In this manuscript, we aimed to compare the quality of sublingual microcirculatory image acquisition between the IDF and SDF devices.

Methods: Using the microcirculatory image quality scoring (MIQS) system, (six categories scored as either $0=$ optimal, $1=$ acceptable, or $10=$ unacceptable), two independent raters compared 30 films acquired using the Cytocam IDF video-microscope, to an equal number obtained with an SDF device. Blinded to the origin of the films, the raters were therefore able to score between 0 and 60 for each film analysed. The scores' distributions between the two techniques were compared.

Results: The median MIQS (95\% Cl) given to the SDF camera was 7 (1.5-12), as compared to $1(0.5-1.0)$ for the IDF device $(p<0.0001)$. Of the six categories assessed by the MIQS, nearly one fifth of the SDF videos were scored as unacceptable for pressure (20\%), content (20\%), and stability (17\%), with focus scoring deficiently $13 \%$ of the time. High agreement between the two raters scoring values was evident, with an intra-class correlation coefficient (ICC) of 0.96 (95 \% Cl: 0.94, 0.98).
\end{abstract}

Conclusions: These results demonstrate that the quality of sublingual microcirculatory image acquisition is superior in the Cytocam IDF video-microscope, as compared to the SDF video-microscope.

Keywords: Microcirculation, Microscopy, Validation, Capillary

\section{Background}

Incident dark field (IDF) imaging is an important technique that allows real time visualisation of the microcirculation [1]. Based upon the illumination of microvessels covered by a thin epithelial layer, it may be thought of as the successor to both orthogonal polarization spectroscopy (OPS) [2], and more recently, sidestream dark field (SDF) imaging [3]. Introduced in 2012, this third generation hand-held camera

\footnotetext{
* Correspondence: e.gilbert@ucl.ac.uk

'University College London Centre for Altitude Space and Extreme Environment Medicine, UCLH NIHR Biomedical Research Centre, Institute of Sport and Exercise Health, 170 Tottenham Court Road, London W1T 7HA, UK Full list of author information is available at the end of the article
}

known as the Cytocam IDF video-microscope (Braedius Medical, Huizen, The Netherlands), was developed in an attempt to overcome many of the previous generations devices technical limitations [1]. These included; i) the limitations imposed by analogue video cameras, ii) the inability to achieve automatic microcirculation analysis, iii) pressure-induced microcirculatory alterations (predominantly caused by the heavy weight of the devices (SDF camera weight $320 \mathrm{~g}$ ), iv) the requirement for hand operated focussing, and v) poor quality of image acquisition [4].

The Cytocam is a lightweight $(120 \mathrm{~g})$, fully digitalised pen-like device (length $220 \mathrm{~mm}$, diameter $23 \mathrm{~mm}$ ) that applies the principle of incident dark field microscopy introduced by Sherman and Cook in 1971 [5]. Blood 
vessels $<100 \mu \mathrm{m}$ in diameter, and $<1000 \mu \mathrm{m}$ below the surface of an organ or mucosal surface, are visualised in a two-dimensional plane through the process of epiillumination [5]. Highly illuminating light emitting diodes (LEDs) enable suitable tissue penetration, and to avoid motion induced blurring secondary to fast moving erythrocytes [6], a very short LED pulse time of two milliseconds is utilised. Image delineation is optimised using a 3.5 megapixel high-resolution sensor, an optical magnification factor of four times, and an optical resolution of more than 300 lines $/ \mathrm{mm}$ - an improvement of $50 \%$ over SDF devices. This is further enhanced with an effective field of view (FOV) almost three times as large as earlier devices $\left(1.55 \times 1.16 \mathrm{~mm}\right.$, FOV area $\left.=1.79 \mathrm{~mm}^{2}\right)$, which may be magnified by a factor of 211 times on the display monitor [1]. Improved focussing is achieved through an integrated distance measurement system, which through the means of a manually adjusting the piezo linear motor via the computer interface, can alter the sensor position in steps of two microns. This novel quantitative focusing mechanism results in an accurate and repeatable focus distance, without having to repeatedly adjust the focus depth for every subsequent measurement. Finally, the IDF video-microscope has the capabilities for direct microcirculation analysis where the images are recorded digitally and analysed automatically. Specialised software automatically detects and quantitatively assesses the vessels' diameters, and the flow velocity of erythrocytes within visualised vessels. Previously analysis of SDF videos required their conversion from analogue to digital images, with subsequent off-line analysis using specialised image processing software [7].

Although the IDF device should have significant superiority, in terms of image quality, over previous technologies this requires confirmation. We therefore set out to directly compare IDF and SDF images in a formalised manner.

\section{Methods}

Thirty films of human sublingual microcirculation obtained using an SDF video-microscope (MicroVision Medical, Amsterdam, Netherlands), were compared to thirty comparable films obtained using the Cytocam IDF video-microscope. The films were picked at random from a database of over 800 SDF and IDF films, all of which were obtained from healthy adult volunteers who had given informed consent. Ethical approval for the study had been obtained from University College London Research and Ethics Committee. Two raters (EGK, JC), blinded to the device on which the video was generated, independently graded the films using the Microcirculation image quality score (MISQ) system [8]. In 2007 a consensus statement that outlined five key principles for optimal image acquisition [9]. These were:

Table 1 The Microcirculation image quality score

\begin{tabular}{|c|c|c|c|c|}
\hline Category & Brief description & Optimal (0) & Acceptable (1) & Unacceptable (10) \\
\hline Illumination & $\begin{array}{l}\text { Brightness and } \\
\text { contrast of video }\end{array}$ & $\begin{array}{l}\text { Even illumination across the entire } \\
\text { field of view. Contrast sufficient to } \\
\text { see small vessels against a } \\
\text { background of tissue. }\end{array}$ & $\begin{array}{l}\text { The video borders on being too } \\
\text { dark or bright to distinguish vessels } \\
\text { from tissue but the vessels are still } \\
\text { identifiable. }\end{array}$ & $\begin{array}{l}\text { The video is oversaturated/too } \\
\text { bright or too dark to make out } \\
\text { analysable features. Insufficient } \\
\text { contrast to resolve flow rate. }\end{array}$ \\
\hline Duration & $\begin{array}{l}\text { Number of frames in } \\
\text { the video clip and } \\
\text { how it represents the } \\
\text { actual pathology }\end{array}$ & $\begin{array}{l}\text { Analysable video segment is } \geq 5 \mathrm{~s} \\
\text { long ( }>150 \text { frames) }\end{array}$ & $\begin{array}{l}\text { Analysable video segment is } 3-5 \mathrm{~s} \\
\text { (between } 90 \text { and } 150 \text { frames) }\end{array}$ & $\begin{array}{l}\text { Analysable video segment }<3 \\
\text { s ( } 90 \text { frames) }\end{array}$ \\
\hline Focus & $\begin{array}{l}\text { Image sharpness in } \\
\text { region of interest }\end{array}$ & $\begin{array}{l}\text { Good focus for all vessels (small } \\
\text { and large) in the entire field of } \\
\text { view. Plasma gaps and red blood } \\
\text { cells are visible. }\end{array}$ & $\begin{array}{l}<1 / 2 \text { field of view is out of focus or } \\
\text { edges of the vessels are slightly out } \\
\text { of focus. }\end{array}$ & $\begin{array}{l}\text { Video is completely out of focus } \\
\text { such that no small vessel can be } \\
\text { seen. }\end{array}$ \\
\hline Content & $\begin{array}{l}\text { Determination of the } \\
\text { types of vessels and/or } \\
\text { presence of occluding } \\
\text { artefacts in the image. }\end{array}$ & $\begin{array}{l}\text { Video is free of occlusions. Good } \\
\text { distribution of large and small } \\
\text { vessels. Less than } 30 \% \text { of the } \\
\text { vessels are looped upon } \\
\text { themselves }\end{array}$ & $\begin{array}{l}\text { Video may have a few artefacts. } \\
\text { Acceptable distribution of large and } \\
\text { small vessels. About 30-50\% of the } \\
\text { vessels are looped. }\end{array}$ & $\begin{array}{l}\text { Most of the field of view has } \\
\text { occluding artefacts such as saliva or } \\
\text { bubbles. More that } 50 \% \text { vessels are } \\
\text { looped upon themselves. }\end{array}$ \\
\hline Stability & $\begin{array}{l}\text { Frame motion that } \\
\text { can be adequately } \\
\text { stabilised without } \\
\text { motion blur }\end{array}$ & $\begin{array}{l}\text { Movement is within } 1 / 4 \text { of the field } \\
\text { of view. No motion blur. }\end{array}$ & $\begin{array}{l}\text { Movement is within } 1 / 2 \text { field of view. } \\
\text { No motion blur. }\end{array}$ & $\begin{array}{l}\text { Movement is greater than } 1 / 2 \text { of the } \\
\text { field of view and/or motion blur in } \\
\text { frame }\end{array}$ \\
\hline Pressure & $\begin{array}{l}\text { latrogenic mechanical } \\
\text { pressure causing } \\
\text { misrepresentation of } \\
\text { flow }\end{array}$ & $\begin{array}{l}\text { Flow is constant throughout the } \\
\text { entire movie. No obvious signs of } \\
\text { artificially sluggish or stopped } \\
\text { flow. Good flow in the largest } \\
\text { vessels. }\end{array}$ & $\begin{array}{l}\text { Signs of pressure (localised sluggish } \\
\text { flow in a specific large vessel), but } \\
\text { flow appears to be unimpeded } \\
\text { based on good flow in most large } \\
\text { vessels. }\end{array}$ & $\begin{array}{l}\text { Obvious pressure artefacts } \\
\text { associated with probe movement, } \\
\text { and/or flow that starts and stops, } \\
\text { reversal of flow. Poor or changing } \\
\text { flow in larger venules. }\end{array}$ \\
\hline
\end{tabular}




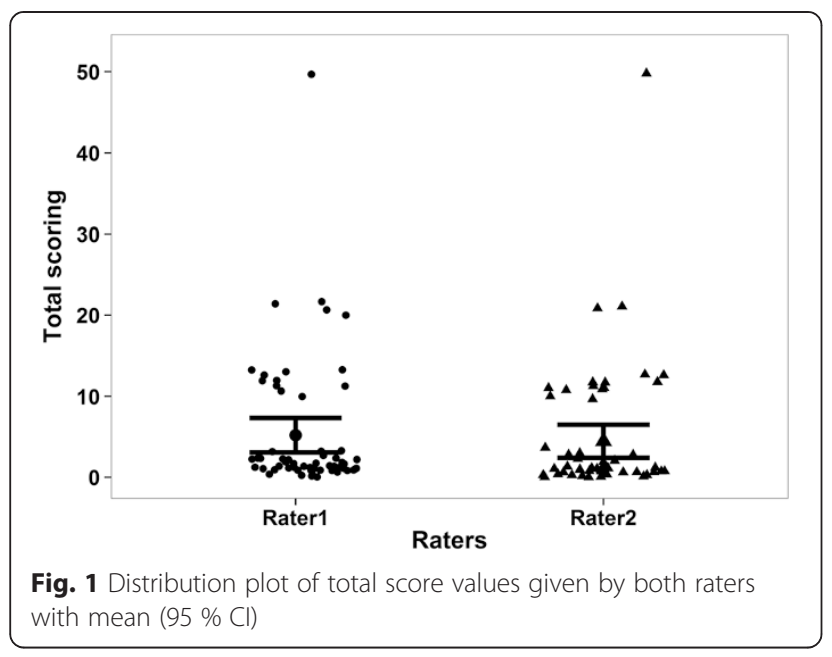

1. Five separate image sites per organ

2. Avoidance of pressure artefacts

3. Elimination of secretions

4. Adequate focus and contrast adjustment

5. High quality recording

In 2013, a more formal approach to grading the quality of image acquisition prior to analysis was described, thereby giving a semi-objective measure of its suitability to be entered for computer analysis and quantification [8]. Six key characteristics of image capture were identified and encompassed within the 'Microcirculation Image Quality Score' (MIQS) (Table 1).

Each of the six categories is graded as 0 (optimal), 1 (acceptable) or 10 (unacceptable). If the total of the six categories is $>10$, then the video is unsuitable for Table 1 analysis and discarded. This somewhat peculiar scoring system is used, for if any one category is designated as unacceptable, it enforces that the video is not used [8].

The agreement between the two raters was assessed using the intra-class correlation coefficient and Bland and Altman limits of agreement. Over the range of scores given, Spearman's correlation coefficient was used to assess the degree of over- or under- estimation of the score by either rater. The Mann-Whitney $U$-test was used to compare the score's distribution between the two techniques. The two-tailed significance level was set at 0.05 , and $\mathrm{R}$ (version 3.1.0) was used for the analyses.

\section{Results}

All 60 videos were analysed by both raters and no problems were encountered. The distribution of the individual total scores by rater is shown in Fig. 1 .

Very good agreement between raters' total scores are evident with an intra-class correlation coefficient of 0.96 (95 \% CI: 0.94, 0.98). In addition, good agreement is evident in Fig. 2 (mean difference (rater2 - rater1): -0.75), and whilst some individual variation may exist as indicated by the slightly wide limits of agreement $(-4.86 ; 3.36)$, no over- or under- estimation trend by either rater was demonstrated (rho $=-0.165, p=0.21$ ). For each device, the breakdown percentages of films scored as optimal, acceptable or unacceptable is presented in Table 2. When comparing the tools, the median score $(95 \% \mathrm{CI})$ given to the SDF video-microscope was $7(1.5 ; 12)$, as opposed to 1 $(0.5 ; 1.0)$ for the IDF video-microscope $(p<0.0001)$. The distribution of these values may be seen in Fig. 3. Examples of images taken with the Incident Dark Field imaging

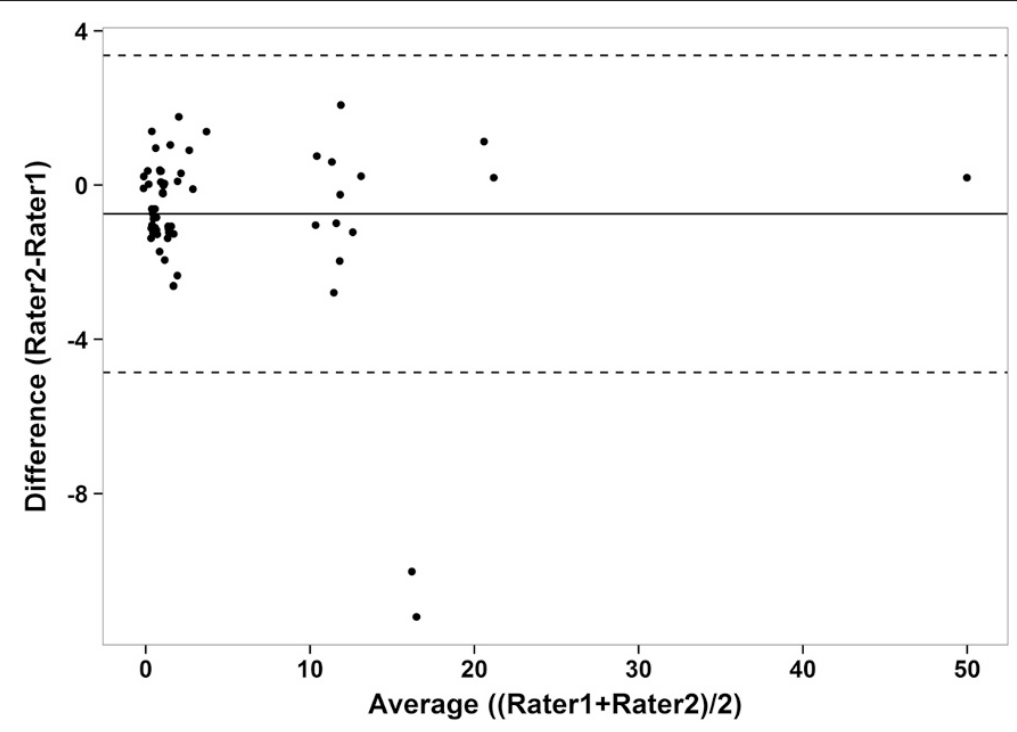

Fig. 2 Bland Altman plot for the agreement between two raters 
Table 2 Percentage (\%) of IDF and SDF films scored as optimal, acceptable, or unacceptable

\begin{tabular}{|c|c|c|c|c|c|c|}
\hline \multirow[t]{2}{*}{ Category } & \multicolumn{2}{|c|}{$\begin{array}{l}\text { Optimal } \\
(\text { Score }=0)\end{array}$} & \multicolumn{2}{|c|}{$\begin{array}{l}\text { Acceptable } \\
(\text { Score }=1)\end{array}$} & \multicolumn{2}{|c|}{$\begin{array}{l}\text { Unacceptable } \\
\text { (Score = 10) }\end{array}$} \\
\hline & IDF & SDF & IDF & SDF & IDF & SDF \\
\hline Stability & 68 & 50 & 32 & 33 & 0 & 17 \\
\hline Pressure & 73 & 67 & 27 & 13 & 0 & 20 \\
\hline Illumination & 92 & 67 & 8 & 30 & 0 & 3 \\
\hline Duration $^{a}$ & 100 & 100 & 0 & 0 & 0 & 0 \\
\hline Focus & 98 & 43 & 15 & 43 & 0 & 13 \\
\hline Content & 88 & 65 & 12 & 15 & 0 & 20 \\
\hline
\end{tabular}

${ }^{\mathrm{a}}$ Images were all cut to 150 frames in length prior to analysis, hence both IDF and SDF demonstrate optimal scores for this category

camera, and Sidestream Dark Field imaging camera can be seen in Additional files 1 and 2.

\section{Discussion}

These results demonstrate for the first time, that the Cytocam IDF video-microscope is superior to the SDF video-microscope in terms of the quality of sublingual microcirculatory image acquisition.

High agreement between the two raters scoring values was demonstrated, and whilst it is evident from the Bland Altman plot that some individual variation existed between raters, neither individual demonstrated a trend in over- or under-estimating the score as the total values increased. Using the total score value to determine if an image was deemed suitable for analysis, (i.e. if given a total score $\geq 10$ renders the video as unacceptable), there was $100 \%$ exact agreement (95\% CI: 94\%; $100 \%$ ) between the two raters.

As to whether the IDF video-microscope was superior to the SDF video-microscope in terms of providing acceptable images for analysis, the median score of 7 given to the SDF images, as opposed to 1 for the IDF videos, indicates that the SDF camera is more prone to produce

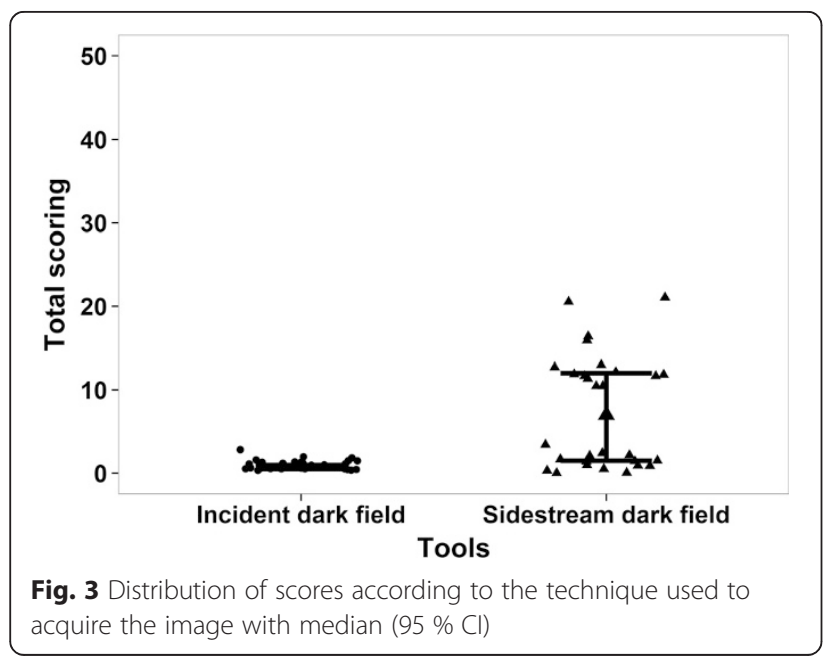

unacceptable results. In this instance, $100 \%$ of the images obtained using the IDF video-microscope were judged to be acceptable for data analysis, as opposed to only $50 \%$ of these data collected using the SDF device. Table 2 demonstrates how the individual components of the MIQS system were scored for both cameras. From this we are able to see which categories SDF scored particularly poorly for as compared to IDF. The IDF video-microscope did not receive any scores of 10 from either rater, however nearly a fifth of the SDF videos were scored as unacceptable for stability (17\%), pressure (20\%), and content (20\%), with focus scoring deficiently $13 \%$ of the time. This indicates superior IDF image acquisition for multiple categories, as opposed to in only one area of data capture.

Although 60 films chosen at random from a large database of images were analysed (30 for each device), a weakness in this manuscript was that no power calculation was performed prior to commencing. This said, the strong statistical significance supports the belief that it was adequately powered. Additionally, as the MIQS still relies on observer input to grade images, it is thus subjective in its film assessment. Nevertheless, it is the most formal approach to image grading we have to date, and the high ICC supports its use.

\section{Conclusion}

In conclusion, these data demonstrate that the IDF videomicroscope provides improved image acquisition of human sublingual microcirculation when compared to the SDF video-microscope. Superior in five out of the six categories comprising the MIQS, the use of IDF offers an advanced insight into the clinical evaluation of the microvasculature.

\section{Additional files}

Additional file 1: Two examples of images obtained using the incident dark field video-microscope. (PNG $1659 \mathrm{~kb}$ )

Additional file 2: Two examples of images obtained using the sidestream dark field video-microscope. (PNG $1188 \mathrm{~kb}$ )

\section{Abbreviations}

FOV: Field of view; IDF: Incident dark field; LED: Light emitting diode; MIQS: Microcirculation image quality score; OPS: Orthogonal polarization spectroscopy; SDF: Sidestream dark field.

\section{Competing interest}

Can Ince has developed SDF imaging and is listed as inventor on related patents commercialized by MicroVision Medical (MVM) under a license from the Academic Medical Center (AMC). He has been a consultant for MVM in the past, but has not been involved with this company for more than 5 years now, except that he still holds shares. Braedius Medical, a company owned by a relative of Can Ince, has developed and designed a hand held microscope called CytoCam-IDF imaging. Dr Ince has no financial relation with Braedius Medical of any sort; he had never owned shares, or received consultancy or speaker fees from Braedius Medical. The authors declare that they had no competing interests. 


\section{Authors' contributions}

E G-K: Design of study, conduct of study, analysis of data, writing manuscript. JC: Conduct of study, analysis of data, writing manuscript. VB: Analysis of data, writing manuscript. Cl: Design of study, writing manuscript. DM: Analysis of data, writing manuscript. All authors read and approved the final manuscript.

\section{Acknowledgements}

The members of the Caudwell Xtreme Everest Research Group are as follows: V. Ahuja, G. Aref-Adib, R. Burnham, A. Chisholm, K. Clarke, D. Coates, M. Coates, D. Cook, M. Cox, S. Dhillon, C. Dougall, P. Doyle, P. Duncan, M. Edsell, L. Edwards, L. Evans, P. Gardiner, M. Grocott, P. Gunning, N. Hart, J. Harrington, J. Harvey, C. Holloway, D. Howard, D. Hurlbut, C. Imray, C. Ince, M. Jonas, J. van der Kaaij, M. Khosravi, N. Kolfschoten, D. Levett, H. Luery, A. Luks, D. Martin, R. McMorrow, P. Meale, K. Mitchell, H. Montgomery, G. Morgan, J. Morgan, A. Murray, M. Mythen, S. Newman, M. O'Dwyer, J. Pate, T. Plant, M. Pun, P. Richards, A. Richardson, G. Rodway, J. Simpson, C. Stroud, M. Stroud, J. Stygal, B. Symons, P. Szawarski, A. Van Tulleken, C. Van Tulleken, A. Vercueil, L. Wandrag, M. Wilson, J. Windsor.

Scientific Advisory Group: B. Basnyat, C. Clarke, T. Hornbein, J. Milledge, J. West. Members of the Xtreme Everest 2 Research Group are as follows: S Abraham, T Adams, W Anseeuw, R Astin, B Basnyat, O Burdall, J Carroll, A Cobb, J Coppel, O Couppis, J Court, A Cumptsey, T Davies, S Dhillon, N Diamond, C Dougall, T Geliot, E Gilbert-Kawai, G Gilbert-Kawai, E Gnaiger, M Grocott, C Haldane, P Hennis, J Horscroft, D Howard, S Jack, B Jarvis, W Jenner, G Jones, J van der Kaaij, J Kenth, A Kotwica, R Kumar BC, J Lacey, V Laner, D Levett, D Martin, P Meale, K Mitchell, Z Mahomed, J Moonie, A Murray, M Mythen, P Mythen, K O'Brien, I. Ruggles-Brice, K Salmon, A Sheperdigian, T Smedley, B Symons, C Tomlinson, A Vercueil, L Wandrag, S Ward, A Wight, C Wilkinson, S Wythe

Scientific Advisory Board: M Feelisch, E Gilbert-Kawai, M Grocott (chair), M Hanson, D Levett, D Martin, K Mitchell, H Montgomery, R Moon, A Murray, M Mythen, M Peters.

\section{Author details}

'University College London Centre for Altitude Space and Extreme Environment Medicine, UCLH NIHR Biomedical Research Centre, Institute of Sport and Exercise Health, 170 Tottenham Court Road, London W1T 7HA, UK. ${ }^{2}$ Statistical Support Service, Population, Policy and Practice Programme, Institute of Child Health, University College London, London, England. ${ }^{3}$ Department of Intensive Care, Erasmus MC University Hospital Rotterdam, 3000 Rotterdam, The Netherlands. ${ }^{4}$ Division of Neonatology, Erasmus MC-Sophia Children's Hospital, Wytemaweg 80, P.O. Box 2060, 3000 CB Rotterdam, Netherlands.

\section{Received: 17 February 2015 Accepted: 24 August 2015}

\section{Published online: 21 January 2016}

\section{References}

1. Aykut G IY, Ince C.: A new generation computer controlled imaging sensor based hand held microscope for quantifying bedside microcirculatory alterations. In Annual update in Intensive Care and Emergency Medicine 2014 Edited by Vincent JL. Springer; 2014:pp. 367-pp. 385.

2. Groner W, Winkelman JW, Harris AG, Ince C, Bouma GJ, Messmer K, et al. Orthogonal polarization spectral imaging: a new method for study of the microcirculation. Nat Med. 1999;5:1209-12

3. Goedhart PT, Khalilzada M, Bezemer R, Merza J, Ince C. Sidestream Dark Field (SDF) imaging: a novel stroboscopic LED ring-based imaging modality for clinical assessment of the microcirculation. Opt Express. 2007;15:15101-14.

4. Mik EG, Johannes T, Fries M. Clinical microvascular monitoring: a bright future without a future? Crit Care Med. 2009;37:2980-1.

5. Sherman H, Klausner S, Cook WA. Incident dark-field illumination: a new method for microcirculatory study. Angiology. 1971;22:295-303.

6. Cerny V. Sublingual microcirculation. Appl Cardiopulm Pathophysiol 2012;16:229-48.

7. Dobbe JSG, Atasever B, Van Zijderveld R, Ince C. Measurement of functional microcirculatory geometry and velocity distributions using automated image analysis. Med Biol Eng Comput. 2008;46:659-70.
8. Massey MJ, Larochelle E, Najarro G, Karmacharla A, Arnold R, Trzeciak S, et al. The microcirculation image quality score: development and preliminary evaluation of a proposed approach to grading quality of image acquisition for bedside videomicroscopy. J Crit Care. 2013;28:913-7.

9. De Backer D, Hollenberg S, Boerma C, Goedhart P, Buchele G, Ospina-Tascon G, et al. How to evaluate the microcirculation: report of a round table conference. Crit Care. 2007;11:R101.

\section{Submit your next manuscript to BioMed Central and take full advantage of:}

- Convenient online submission

- Thorough peer review

- No space constraints or color figure charges

- Immediate publication on acceptance

- Inclusion in PubMed, CAS, Scopus and Google Scholar

- Research which is freely available for redistribution

Submit your manuscript at www.biomedcentral.com/submit 